\title{
PROSTAGLANDIN F2-ALPHA EYE DROPS (BIMATOPROST) IN GRAVES' ORBITOPATHY: A RANDOMISED CONTROLLED DOUBLE MASKED CROSSOVER TRIAL (BIMA TRIAL)
}

\author{
Mohd Shazli Draman1, 5 PhD, DramanYusofMS@cardiff.ac.uk, \\ Daniel S Morris2 FRCSEd (Ophth), dsm@doctors.org.uk \\ Sam Evans2 FRCOphth, drsamevans@mac.com \\ Anjana Haridas2 FRCOphth, anjana@doctors.org.uk \\ Julie Pell1 PgC, PellJC@cardiff.ac.uk
}

Rosemary Greenwood3 MSc, Rosemary.Greenwood@uhbristol.nhs.uk

Chris Foy4 MSc, Chris.Foy@glos.nhs.uk

Peter Taylor 1 MSc, TaylorPN@cardiff.ac.uk

Pakinee Pooprasert1, PooprasertP@cardiff.ac.uk

Ilaria Muller1 PhD, Mullerl4@cardiff.ac.uk

Lei Zhang1 PhD, ZhangL14@cardiff.ac.uk

Carol Lane2 FRCP, carollanedm@gmail.com

Onyebuchi Okosieme1 MD, buchiokosieme@hotmail.com

Marian Ludgate1 PhD, Ludgate@cardiff.ac.uk

Colin Dayan1 PhD, DayanCM@cardiff.ac.uk

1 Thyroid Research Group, Cardiff University School of Medicine, Heath Park, Cardiff, CF14 $4 X N, U K$.

2 Department of Ophthalmology, University Hospital of Wales, Heath Park, Cardiff, CF14 4XW, UK. 


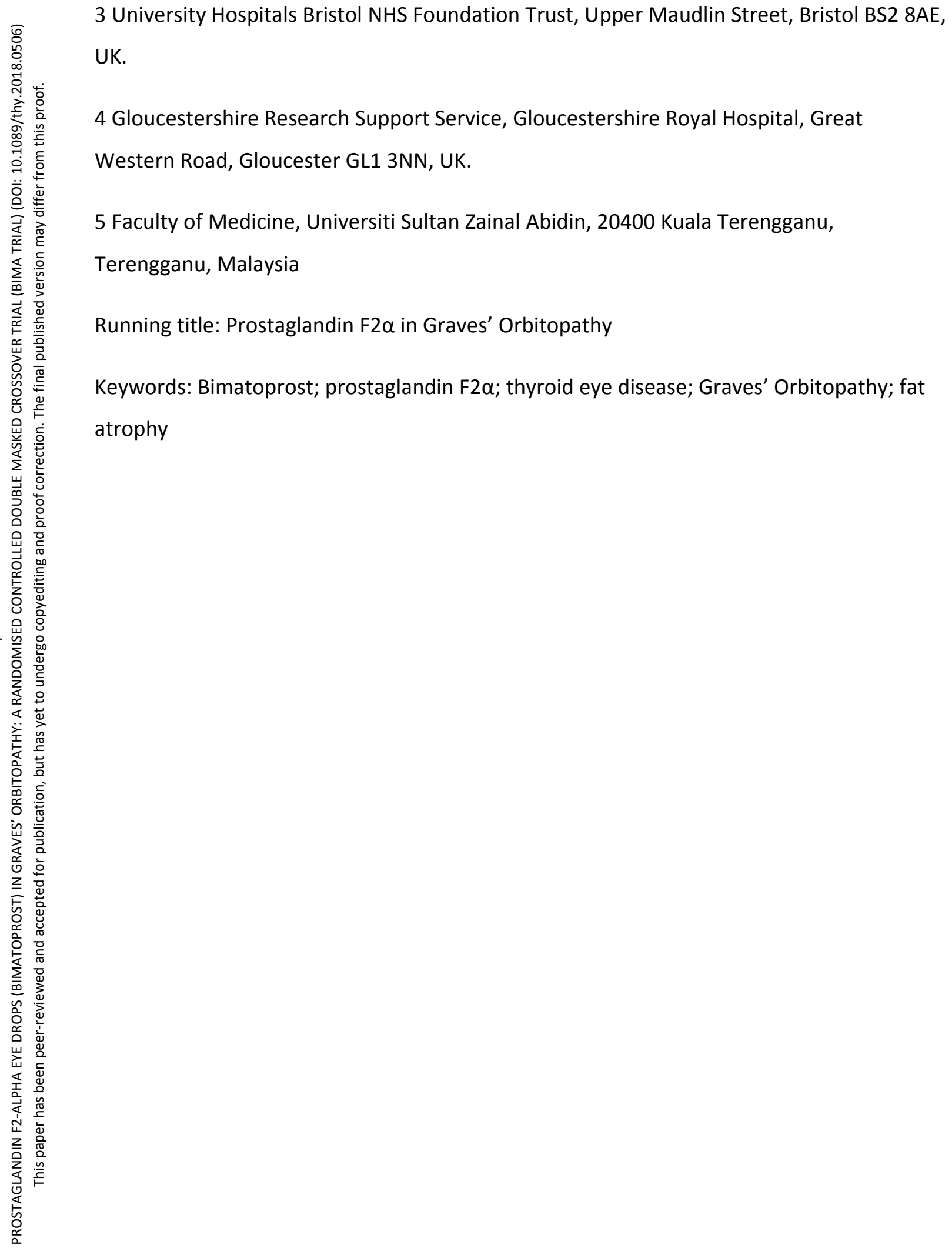


Abstract

Background: Previous in vitro experiments have demonstrated that PGF2 $\alpha$ reduced proliferation and adipogenesis in a murine cell line and human orbital fibroblasts derived from subjects with inactive Graves' orbitopathy (GO). The objective of this study was to determine if the PGF2 $\alpha$ analogue Bimatoprost is effective at reducing proptosis in this population.

Methods: A randomized controlled double-masked crossover trial was conducted in a single tertiary care academic medical center. Patients with longstanding, inactive GO but persistent proptosis ( $>20 \mathrm{~mm}$ in at least one eye) were recruited. Allowing for a $15 \%$ dropout rate, 31 patients ( 26 females) were randomized in order to identify a treatment effect of $2.0 \mathrm{~mm}$ ( $p=0.05$, two-sided paired t-test, power 0.88 ). Following informed consent, participants were randomized to receive Bimatoprost or placebo for three months after which they underwent a two-month washout, before switching to the opposite treatment. The primary outcome was the change in exophthalmometry readings over the two 3-month treatment periods.

Results: The mean exophthalmometer at baseline was 23.6 (range 20.0-30.5) $\mathrm{mm}$ and the mean age was 55 (range 28-74) years. The median duration of GO was 7.6 (IQR 3.6-12.3) years. The majority were still suffering from diplopia (61.3\%) with bilateral involvement (61.3\%). Using multilevel modeling adjusted for baseline, period and carryover, Bimatoprost resulted in a $-0.17 \mathrm{~mm}$ (reduction) exophthalmometry change $(95 \% \mathrm{Cl}-0.67$ to +0.32$) \mathrm{p}=0.490$. Intraocular pressure was reduced $-2.7 \mathrm{mmHg}(95 \% \mathrm{Cl}-4.0$ to -1.4$)$ $p=0.0070$. One patient showed periorbital fat atrophy (PAP) on treatment which resolved on stopping treatment. Independent analysis of proptosis by photographic images (all subjects) and subgroup analysis on monocular disease $(n=12)$ did not show any apparent benefit.

Conclusion: In inactive GO, Bimatoprost treatment over a 3-month period does not result in an improvement in proptosis. 


\section{INTRODUCTION}

Graves' orbitopathy (GO) is the commonest extrathyroidal manifestation of Graves' hyperthyroidism. Proptosis may persist after inflammation has subsided in the late "burnt out" phase of GO and the persistent disfigured appearance of the eyes is a source of significant psychological distress and impaired quality of life for sufferers (1). There are no specific medical treatments that target orbital volume reduction in late-stage disease. A UK nationwide survey of patients with GO revealed low satisfaction levels with existing therapies (2).

The main pathological features of GO include expansion of orbital tissue fat, muscle, mononuclear cell infiltration of orbital connective tissue and extraocular muscle, and tissue remodeling, a process that can culminate in fibrosis and diminished eye motility (3). A key mechanism underlying $\mathrm{GO}$ is an increase in adipogenesis and muscle associated secretion of glycosaminoglycans (GAG) in the orbit, resulting in an increase in orbital volume and exophthalmos (protrusion of the eye) $(4,5)$. The opposite effect, enophthalmos (recession of the eye into the orbit), has been described in patients with glaucoma treated with daily Bimatoprost (prostaglandin F2 alpha, PGF2 $\alpha$ ), a prostaglandin analogue used topically in the management of intraocular hypertension (glaucoma). Cases of enophthalmos developing in patients treated with Bimatoprost and other PGF2 $\alpha$ analogues have been reported worldwide, albeit in small numbers (6-10). This side effect is more noticeable if only one eye is exposed to treatment as the treated eye is easily comparable with the unexposed eye. However, since most patients receive treatment to both eyes it is possible that the incidence of enophthalmos in Bimatoprost treated patients has been underestimated.

A possible mechanism by which PGF2 $\alpha$ agonists might produce enophthalmos is through reduction of orbital fat volume (6). A PGF2 $\alpha$ receptor agonist has been shown to be a potent inhibitor of adipose tissue differentiation in new-born rat precursor cells (11). This raises the possibility that PGF2 $\alpha$ exerts direct effects on adipose tissue precursors. We have confirmed this finding in in vitro studies in our laboratory using 3T3-L1 cell lines and human primary orbital fibroblast cultures (12). This is further supported by Eftekhari et al. 
who reported that retrobulbar Bimatoprost injections in rats showed histologic evidence of orbital fat atrophy (13). Thus, PGF2 $\alpha$ agonists may be effective in reducing orbital fat expansion, ameliorating proptosis, and thus improving quality of life in patients with active and/or inactive disease.

Rehabilitative surgery is the mainstay of treatment for the late disease phase. However, surgery is not always successful in reducing proptosis and carries the associated risks of anesthesia and local complications (14). Recently Teprotumumab, a human monoclonal antibody inhibitor of IGF-1R has been shown to reduce proptosis in patients with active GO (15), whilst radiotherapy is of questionable benefit in conjunction with steroids (16). However, there remains a major unmet need for medical therapies to reduce residual proptosis in the late-phase (inactive) of GO, a disease stage in which disfigurement and impairment of ocular function persist after resolution of the initial inflammatory process and which affects 5-10 times as many people as the early active phase (17). In our in vitro study, the majority of samples studies were from patients with inactive GO, and PGF2 $\alpha$ was noted to reduce proliferation and adipogenesis in orbital fibroblasts from both $\mathrm{GO}$ and non-GO tissue (12). Even in "burnt out" disease, orbital fibroblasts from GO have a higher proliferation and adipogenesis potential than cells from normal orbits (12). We therefore designed a randomized double-masked cross-over clinical study to evaluate the impact of Bimatoprost at reducing proptosis in patients with $\mathrm{GO}$.

\section{METHODS}

The trial was conducted according to the protocol and in compliance with the principles of the Declaration of Helsinki (1996), the principles of Good Clinical Practice (GCP) and in accordance with Medicines for Human Use (Clinical Trials) Regulations 2004, as amended in 2006, the Research Governance Framework for Health and Social Care, the Data Protection Act 1998 and other regulatory requirements as appropriate. The trial has been approved by a local NHS Research Ethics Committee (REC, registration number: 14/WA/0081), the Medicines and Healthcare Products Regulatory Agency (MHRA, registration number: 21323/0043/001-0001) and is registered with ClinicalTrials.gov 
(registration number: NCT02059655) and the International standard randomized controlled trial network (ISRCTN, registration number: ISRCTN46696624).

This was a single center randomized controlled double-masked crossover trial of Bimatoprost in GO. Allocation of subjects was by remote computerized web-based randomization and minimization over 2 identified factors (degree of proptosis and uni/bilateral eyes involvement) to ensure a balance between the 2 trial arms.

Patients were recruited from the multidisciplinary GO clinic at University Hospital of Wales. All patients had had a previous diagnosis of GO defined by the presence of one or more of the following features: soft tissue changes in the eye, proptosis, extraocular muscle dysfunction, corneal abnormalities, and optic nerve involvement. The inclusion criteria were stable GO with no reported change in proptosis for at least 6 months, inactive disease with a clinical activity score $<3$, proptosis (subjective unilateral proptosis confirmed by asymmetry in exophthalmometry of $>2 \mathrm{~mm}$ or greater than $20 \mathrm{~mm}$ on exophthalmometry measurement in one eye), euthyroid (FT3 and FT4 in the reference range) and, if female, using a reliable form of contraception during the trial. The exclusion criteria were age less than 18 years old, dysthyroid optic neuropathy, pregnancy/lactation, on therapy for glaucoma, systemic steroid use, patients with risk factors for cystoid macular edema, iritis or uveitis and allergies to Bimatoprost or preservative. Patients were assessed at screening visit at least 2 weeks prior to a first trial visit to ensure that they had inactive disease. Patients were allocated either Bimatoprost or placebo for 3 months, followed by 2 months washout period before crossing over to the opposite treatment. Bimatoprost 0.03\% (Lumigan ${ }^{\circledR}$ Allergan) or placebo (Blumont Healthcare) was administered at a dose of one drop in the affected eye/eyes once daily between 18:00 midnight starting from the day of allocation. To enhance masking, the placebo contained artificial tears with a similar preservative (Benzalkonium chloride) which will replicate any mild stinging sensation experienced with Bimatoprost. Patients were allowed to use preservative free eye drops for symptomatic dry eyes if needed during the trial which had to be applied at least 30 minutes before/after trial drops application. No other eye drops were allowed during the trial period. 
The primary outcome was the change in proptosis with Bimatoprost using the mean improvement of the two eyes where both have been treated. A change of $>2.0 \mathrm{~mm}$ in proptosis is considered to be clinically relevant $(18,19)$. Assuming a standard deviation of $2.5 \mathrm{~mm}$ in proptosis measurements in patients with $\mathrm{GO}$ as previously reported $[19,20]$, we calculated that 26 participants would be needed to be able to identify a treatment effect of $2.0 \mathrm{~mm}$ as statistically significant ( $p=0.05$, two-sided paired t-test, power 0.88 ). Allowing for a $15 \%$ dropout rate/incomplete datasets, we recruited 31 participants.

At each visit, patients underwent ophthalmological assessment including assessment of proptosis (using an Oculus $@$ exophthalmometer), intraocular pressure in primary position and up gaze, logMAR visual acuity, clinical activity score (CAS), palpebral aperture, Gorman's diplopia score, corneal integrity, quality of life questionnaires (GO quality of life questionnaire (GO-QOL) and EQ-5D-5L) and health economic assessment using modified client service receipt inventory (CSRI) for GO (see supplementary material - BIMA protocol). Color photographs of the eye in the lateral and anterior views were taken according to a standard operating procedure (see supplementary material - SOP). Photograph exophthalmometry measurements were made following $200 \%$ magnification from standard view either from lateral canthus or nasal bridge to the corneal apex by a masked assessor. Any adverse events were recorded in the patient's diary. Thyroid function tests (TSH, FT3, FT4) were performed at the beginning, middle and end of trial visits to ensure patients remained euthyroid. Secondary outcomes were change in GO$\mathrm{QOL}$, change in intraocular pressures (IOP) in primary and chin forward position, side effect profiles of Bimatoprost, and health economic evaluation. The ophthalmology assessment was carried out by either one of two assessing ophthalmologists. We conducted an initial exophthalmometer alignment phase whereby the assessors were calibrated by multiple exophthalmometer readings on the same non-trial subjects in the clinic and adjustments were made to ensure their readings were comparable. Subjects were not necessarily assessed by the same assessor at each time point. In order to ensure maintenance of masking, during each trial visit the assessors did not have access to baseline values or any prior measurements and clinical notes. 
The mean change in proptosis measurement in the placebo phase and Bimatoprost phase was compared with a paired t-test. This was carried out using the mean improvement of the two eyes where both have been treated or the change in one eye where only one was treated. Multilevel model in STATA version 12.1 (STATACORP, College Station, TX) using demographic and clinical variables (including baseline, the order of treatment and carryover effects) was also used to adjust for unexplained variance and in order to obtain better estimates of effect size with tighter confidence intervals. The results are expressed as an effect in millimeters from the treatment arm controlling for the placebo effect with 95\% confidence intervals $(95 \% \mathrm{Cl})$ and p-values. Secondary and other outcomes were summarized with descriptive statistics.

There were 3 patients who were deemed to be protocol non-compliant with inclusion criteria who had FT4 levels above the reference range with normal FT3 during the screening period. This was due to a misinterpretation of the inclusion criteria requiring both a normal FT4 and FT3 (rather than either FT4 or FT3). These three patients were clinically euthyroid during randomization. A sensitivity analysis was done after the exclusion of these three subjects to determine any effect on the study conclusions.

RESULTS

Recruitment and retention

Seventy-two patients were invited initially of which 33 agreed for the trial enrolment. One patient was ineligible on screening and one patient chose not to take part due to fear that Bimatoprost might change her iris color. Thirty-one patients were subsequently randomized and underwent the first phase of the trial successfully. Unfortunately, one patient from the Bimatoprost starting group died at the end of first washout period due to pulmonary embolism which was not considered to be related to the investigational product. Therefore, 30 patients were entered into the second phase of the trial. One patient from the placebo starting group did not return for visit 4 (end of second phase assessment) due to the withdrawal of consent. Twenty-nine patients entered the second washout phase and completed the trial (Figure 1). 
Demographic and baseline characteristics

Out of 31 patients, there was a female preponderance with a 5:1 ratio and a mean age of 55.2 (range 28-74) years. The median duration of GO was 7.6 (IQR 3.6-12.4) years. The majority were smokers at diagnosis $(74.2 \%)$, but this reduced to $38.7 \%$ after the diagnosis. $61 \%$ were still suffering from diplopia (19/31) and 19/31 (61\%) had bilateral involvement. There was a good balance between the 2 treatment allocations with some differences in smoking history but not at trial entry and more patients with constant diplopia in the Bimatoprost first starting group (Table 1). Thyroid function tests were unchanged throughout the study period.

Inter-operator comparison

Fifteen non-trial patients were assessed by the 2 assessors by exophthalmometry after a period of calibration between assessors involving 5 patients. Compared to assessor 1 , the regression coefficient of assessor 2 was $0.93(95 \% \mathrm{Cl} 0.83$ to 1.03$) \mathrm{mm}$. There was a positive Pearson correlation with $r=0.9652(p<0.0001)$ between the 2 assessors (Supplement Figure 1 and 2).

Primary outcome analysis

The mean baseline exophthalmometer readings of treated eyes in the Bimatoprost starting group was 24.1 (SD 2.9) $\mathrm{mm}$ and 23.1 (1.9) $\mathrm{mm}$ in the placebo starting group (Table 1). The mean change across all affected eyes in the Bimatoprost phase was $+0.17 \mathrm{~mm}(95 \% \mathrm{Cl}$ 0.35 to +0.69$)$ versus $+0.26 \mathrm{~mm}(95 \% \mathrm{Cl}-0.51$ to +1.03$)$ in the placebo phase. This was not statistically different with a $p$ value $=0.845$ (Figure 2). A sensitivity analysis was done after exclusion of the three protocol non-compliant subjects. There was no difference between the 2 groups $p=0.727$. Using pkcross function on the STATA, there were no period $(p=0.38)$ or carryover $(p=0.46)$ effects observed.

Multilevel modelling

Data were also analyzed using a multilevel model in STATA which will also enables to use one data point for those patients who were unwilling or unable to proceed to the second 
phase of the protocol, thus using all available data as efficiently as possible. In this process, each patient's eye outcome measured was nested within each individual patient. Crude analysis adjusted for baseline (model 1 ) did not show any treatment effect on the exophthalmometer readings with a coefficient of $-0.27 \mathrm{~mm}(95 \% \mathrm{Cl}-1.43$ to +0.89 , $p=0.648)$. Adding multilevel modelling correcting for baseline and phase of treatment (model 2) resulted in a treatment coefficient of $-0.17 \mathrm{~mm}(95 \% \mathrm{Cl}-0.67$ to +0.32$)$, again not statistically significant $p=0.490$. Carryover adjustment was omitted because of collinearity with the phase of treatment. Adding the assessors to the model did not improve the model with a treatment effect of $-0.16 \mathrm{~mm}(95 \% \mathrm{Cl}-0.65$ to $0.33, \mathrm{p}=0.531)$ and an assessor coefficient of $-0.34 \mathrm{~mm}(95 \% \mathrm{Cl}-0.96$ to $0.27, \mathrm{p}=0.274)$. Removing 3 patients with protocol deviation resulted in a model 2 treatment coefficient of $-0.06 \mathrm{~mm}(95 \% \mathrm{Cl}-0.56$ to +0.45 , $\mathrm{p}=0.827)$ and a model 3 treatment coefficient of $-0.04 \mathrm{~mm}(95 \% \mathrm{Cl}-0.55$ to $+0.46, p=$ $0.861)$. Using response to $10 \%$ drop in IOP as a surrogate marker for compliance showed no statistically significant treatment effect on proptosis as measured on the exophthalmometer (Table 2).

Exophthalmometer change in patients with unilateral proptosis

There were 12 patients with unilateral proptosis. In these patients, only one eye with proptosis was treated whilst the other eye was not treated and served as a control. Analysis of the exophthalmometer reading revealed predicted baseline exophthalmometer differences with a higher exophthalmometer mean in the treated eye of $22.17 \mathrm{~mm}(95 \% \mathrm{Cl}$ 21.16 to 23.17$)$ versus $20.33 \mathrm{~mm}(95 \% \mathrm{Cl} 19.14$ to 21.52$)$ in the untreated eye ( $p=0.0032)$. Treatment with Bimatoprost did not result in a statistically significant reduction in exophthalmometer results with a mean change of $+0.08 \mathrm{~mm}(95 \% \mathrm{Cl}-0.66$ to +0.82$)$ in the treated eye compared to $0.67 \mathrm{~mm}(95 \% \mathrm{Cl}-0.58$ to +1.92$)$ in the untreated eye $(p=0.1516)$.

Exophthalmometry and photographic assessment correlations

Proptosis measurements were also made by photographic assessment of the patient photos taken during the trial. The measurements were taken either from the lateral canthus or nasal bridge to the corneal apex by a masked assessor (Figure 3). All data from 5 visits were used for this analysis. Results of the Spearman correlation indicated that 
there was a significant positive association between exophthalmometer and lateral canthus measurements (Spearman rho 0.609, $p<0.0001$ ). There was a significant negative correlation between exophthalmometer and nasal bridge measurements (Spearman rho $0.396, p<0.0001$ ) (see Figure 4 and Figure 5). The later finding was expected as the measurement was taken from nasal bridge to corneal apex, i.e. the more proptosis, the lesser the distance between the corneal apex to the nasal bridge.

There was no difference between placebo and Bimatoprost with regard to photo measurement results of the lateral canthus to corneal apex distance with placebo (mean change of $+1.30 \mathrm{~mm} ; 95 \% \mathrm{Cl}-0.74$ to +3.35$)$ compared to Bimatoprost $+0.98 \mathrm{~mm}(95 \% \mathrm{Cl}-$ 1.25 to +3.20$)(p=0.8160)$. Similarly, there was no difference between placebo and Bimatoprost nasal bridge to corneal apex measurement results with placebo treatment resulting in a mean change of $-0.50 \mathrm{~mm}(95 \% \mathrm{Cl}-4.18$ to +4.08$)$ compared to Bimatoprost with a mean change of $+1.30 \mathrm{~mm}(95 \% \mathrm{Cl}-5.65$ to +8.25$)(p=0.6870)$. There was no significant change observed in the subset of patients with unilateral proptosis $(n=12)$ with Bimatoprost treatment resulting in a lateral cantus measurement change of $-0.32 \mathrm{~mm}$ $(95 \% \mathrm{Cl}-4.41$ to +3.76$)$ versus untreated of $+1.09 \mathrm{~mm}(95 \% \mathrm{Cl}-4.07$ to +6.26$)(p=0.5252)$. Likewise, Bimatoprost treatment resulted in a nasal bridge measurement change of +3.10 $\mathrm{mm}(95 \% \mathrm{Cl}-13.53$ to +19.73$)$ compared to the untreated eye of $+6.43 \mathrm{~mm}(96 \% \mathrm{Cl}-3.99$ to +16.86$)(p=0.6318)$.

Secondary outcome analysis

In general, patients scored highly on the total visual score using the GO-QOL questionnaire throughout trial visits with a range of mean total visual scores of 79 to 85 . With regard to treatment, there was no change in the total visual scores. The change was calculated by subtracting post-treatment score against baseline score. A positive value would indicate an improvement in the quality of life and a change of at least 6 points was considered a minimal clinically important difference. The mean changes for Bimatoprost was $0.8(95 \%$ 7.1 to 8.7$)$ versus placebo $-0.6(95 \% \mathrm{Cl}-6.5$ to 5.2$)(p=0.7930)$. There was a good negative correlation between the Gorman diplopia score and the total visual score (Spearman's rho 
$-0.5118, p<0.0001)$. This negative correlation persisted even after removing patients treated with prisms (Spearman rho $-0.5111, \mathrm{p}<0.0001$ ).

Patients scored lower throughout trial visits with regard to total appearance score with the mean ranging from 52 to 58 . No change in total appearance score was seen at 3 months after Bimatoprost treatment with a mean of 0.4 (95\% Cl -3.6 to 4.5$)$ versus placebo 2.2 (95\% Cl -5.2 to 9.5) ( $p=0.0 .6897)$. There was no correlation between the Gorman diplopia score and the total appearance score (Spearman's rho $-0.0785, p=0.3396)$. This correlation became significant after removing patients treated with prisms, albeit remaining a rather weak association (Spearman rho -0.2282 , p $<0.0115$ ).

During trial visits, the mean IOP measured in the primary position was within the normal reference range between 16 to $18 \mathrm{mmHg}$. As expected, Bimatoprost caused a reduction in IOP with a mean change of $-2.7 \mathrm{mmHg}(95 \% \mathrm{Cl}-4.0$ to -1.4$)$ compared to placebo with a mean change of $0.3 \mathrm{mmHg}(95 \% \mathrm{Cl}-1.4$ to 2.1$)$ ( $p=0.007)$, consistent with compliance with the medication. We found chin forward position did not alter intraocular pressure significantly. There was no difference in NHS health economics consumption between Bimatoprost and placebo period.

Bimatoprost was associated with patient-reported conjunctival hyperemia and headache (Supplementary Table 2). Apart from patient-reported side effects, objective assessments of photographs were also made by an independent masked assessor. Patients treated with Bimatoprost had a higher than placebo detectable skin discoloration, eyelashes elongation, and eyelid redness (Supplementary Table 3). Only 1 patient (3.2\%) developed observable periorbital fat atrophy which was the desired effect in this trial (Figure 6). This was a 57-year-old female patient who was a current smoker with 5 years history of GO. She was previously treated with IV steroids, radiotherapy, cyclosporin and Rituximab. The fat atrophy lasted for 2 months following the washout period. In this patient, at baseline the right eye exophthalmometer measurement was $23 \mathrm{~mm}$ and the left eye was $24 \mathrm{~mm}$. Following 3 months on Bimatoprost, there was a reduction of $2 \mathrm{~mm}$ of the right eye and 1 $\mathrm{mm}$ of the left eye. These then returned to baseline following a washout period of 2 months. 
DISCUSSION

This is the first clinical trial assessing the effects of PGF2 $\alpha$ in stable inactive GO. This trial did not show any clinical benefit of Bimatoprost on reducing proptosis. This finding was confirmed on photographic measurements and despite the effect on IOP and appearance changes (lashes elongation, conjunctival hyperemia and skin changes) suggesting good compliance. The standard deviation was consistent with power calculations suggesting that we were not underpowered and unlikely that the effect was missed. This is in contrast with the in vitro findings $(20,21)$, anecdotal case reports in people without GO (6-8) suggesting adipocyte differentiation inhibition with Bimatoprost. The findings also contrast with the results obtained with Teprotumumab, a human monoclonal antibody inhibitor of IGF-IR shown to reduce proptosis. The success of Teprotumumab might be attributed to the fact it was used in active $\mathrm{GO}$ and it targets a different pathophysiological mechanism.

The lack of the effects in the primary analysis might be due to several explanations. We are fully aware that the 2 main mechanisms of $\mathrm{GO}$ are adipogenesis and hyaluronan accumulation (22). In the burnt out stage, fibrosis will predominate. The topical eye drops might be absorbed less freely due to the inflammatory/fibrosis process. In the search for stable disease in order to show the effect of PGF2 $\alpha$, we might have chosen the wrong stage of the disease which is predominantly caused by hyaluronan deposition or fibrosis rather than adipogenesis. Adipogenesis starts early in the disease and it has been shown that it may continue even in the inactive disease stage (23). PGF2 $\alpha$ inhibits adipogenesis per se but does not affect lipolysis and hence has no impact on an already fully mature adipocyte (20). Not all glaucoma patients treated with PGF2 $\alpha$ develop periorbital fat atrophy with an estimated incidence of $24.1 \%$ (24). Some patients with GO have predominantly fat excess whilst the others have muscle predominant disease (25). This suggests the possibility of a subgroup of subjects that are more susceptible to the effect of Bimatoprost who could be identified by screening using orbital imaging. Perhaps a treatment of 3 months' duration is not long enough to see the intended reduction in proptosis. However, this seems unlikely as there was sufficient time to see fat atrophy. Compliance also might be an issue, although the changes in IOP on treatment suggest this is unlikely, and we did not find a statistically significant treatment effect after adjustment 
made for compliance using a reduction in IOP as a surrogate marker. Periorbital fat atrophy was observed in 1 subject (3\%) of our patient population suggesting that periorbital fat atrophy is different from general fat reduction. Perhaps the periorbital effect seen is mediated via a different mechanism such as activation on matrix metalloproteinases (26).

The assessment of exophthalmos was robust with exophthalmometer and supported with photographic assessments conducted by an assessor who was masked to the treatment phase. In the current study, we had 2 trained assessors. Assessors were assigned to the trial patients at each trial visit according to assessors' availability. To reduce inter-rater variation, our assessors were calibrated by multiple exophthalmometer readings on the same non-trial subjects in the clinic and adjustments were made to ensure their readings were comparable. Photographic measurements also provided further independent confirmation of the exophthalmometer results.

The strengths of this trial include its cross-over design with no period or carry-over effects. There was good patient retention and good compliance as evidenced by the fall in IOP in the treatment phase. The success of the masking process was analyzed by asking patients and assessors directly and by the independent masked assessor on photographic assessment. Assessors guessed treatment allocation incorrectly in $56.7 \%$ of the patients. Approximately $27 \%$ of the patients on placebo thought that the prominence of their eyes improved compared to $43 \%$ treated with Bimatoprost. Just above $40 \%$ of the patients in both phases preferred the treatment. $43 \%$ of subjects in the placebo phase were unsure of treatment allocation and a further $10 \%$ guessed incorrectly; $29 \%$ in the Bimatoprost phase were unsure and $32 \%$ guessed incorrectly when asked about their treatment allocation suggesting that masking was successful.

In summary, Bimatoprost treatment over 3 months in inactive GO does not result in improvements in proptosis and this information should prevent clinicians trialing this approach further and causing side-effects unnecessarily. Future trials should be done on early stage GO and active disease. Periorbital fat atrophy appears to be an idiosyncratic reaction to Bimatoprost rather than a routine event in inactive GO patients. The BIMA 
study has demonstrated that crossover studies can be performed reliably in patients with persistent proptosis due to thyroid eye disease and that this study design is acceptable to patients. The BIMA study also has shown that over $60 \%$ of patients with residual proptosis in thyroid eye disease also have double vision (diplopia). IGF-1R antagonists have shown promise in active disease but still only surgical treatments are available in burnt out disease. Hence, there are still large unmet needs in this patient group.

Acknowledgments. Funding was provided by Health and Care Research Wales under Research for Patient and Public Benefit Wales Scheme.

Disclosure Statement. No competing financial interests exist for any author.

Corresponding author:

Mohd Shazli Draman

Thyroid Research group, Systems Immunity Research Institute, School of Medicine, Cardiff University, Heath Park, Cardiff, CF14 4XN, UK.

Email: dramanyusofms@cardiff.ac.uk.

Tel: (+44) $02920745457 \quad$ Fax: (+44) 02920744671 
References:

1. Terwee CB, Gerding MN, Dekker FW, Prummel MF, Wiersinga WM 1998

Development of a disease specific quality of life questionnaire for patients with Graves' ophthalmopathy: the GO-QOL. Br J Ophthalmol 82:773-779.

2. Estcourt S, Hickey J, Perros P, Dayan C, Vaidya B 2009 The patient experience of services for thyroid eye disease in the United Kingdom: results of a nationwide survey. European journal of endocrinology / European Federation of Endocrine Societies 161:483487.

3. Eckstein AK, Johnson KT, Thanos M, Esser J, Ludgate M 2009 Current insights into the pathogenesis of Graves' orbitopathy. Horm Metab Res 41:456-464.

4. Zhang L, Bowen T, Grennan-Jones F, Paddon C, Giles P, Webber J, Steadman R, Ludgate M 2009 Thyrotropin receptor activation increases hyaluronan production in preadipocyte fibroblasts: contributory role in hyaluronan accumulation in thyroid dysfunction. J Biol Chem 284:26447-26455.

5. Zhang L, Baker G, Janus D, Paddon CA, Fuhrer D, Ludgate M 2006 Biological effects of thyrotropin receptor activation on human orbital preadipocytes. Invest Ophthalmol Vis Sci 47:5197-5203.

6. Peplinski LS, Albiani Smith K 2004 Deepening of lid sulcus from topical bimatoprost therapy. Optom Vis Sci 81:574-577.

7. Filippopoulos T, Paula JS, Torun N, Hatton MP, Pasquale LR, Grosskreutz CL 2008 Periorbital changes associated with topical bimatoprost. Ophthal Plast Reconstr Surg 24:302-307.

8. Yam JC, Yuen NS, Chan CW 2009 Bilateral deepening of upper lid sulcus from topical bimatoprost therapy. Journal of ocular pharmacology and therapeutics : the official journal of the Association for Ocular Pharmacology and Therapeutics 25:471-472. 
9. Nakakura S, Yamamoto M, Terao E, Nagatomi N, Matsuo N, Fujisawa Y, Fujio Y, Tabuchi H, Kiuchi Y 2015 Prostaglandin-associated periorbitopathy in latanoprost users Clin Ophthalmol. Vol 9, 51-56.

10. Sakata R, Shirato S, Miyata K, Aihara M 2014 Incidence of deepening of the upper eyelid sulcus in prostaglandin-associated periorbitopathy with a latanoprost ophthalmic solution Eye (Lond). Vol 28, 1446-1451.

11. Serrero G, Lepak NM, Goodrich SP 1992 Prostaglandin F2 alpha inhibits the differentiation of adipocyte precursors in primary culture. Biochemical and biophysical research communications 183:438-442.

12. Draman MS, Grennan-Jones F, Zhang L, Taylor PN, Tun TK, McDermott J, Moriarty P, Morris D, Lane C, Sreenan S, Dayan C, Ludgate M 2013 Effects of Prostaglandin F-2 alpha on Adipocyte Biology Relevant to Graves' Orbitopathy. Thyroid 23:1600-1608.

13. Eftekhari K, Vagefi MR, Lee V, Hui JZ, Zhu M, Dine K, Anderson RL, Koeberlein B, Sulaimankutty R, Shindler KS 2017 In Vivo Effects of Retrobulbar Bimatoprost Injection on Orbital Fat. Ophthal Plast Reconstr Surg.

14. Boboridis KG, Bunce C 2011 Surgical orbital decompression for thyroid eye disease. Cochrane Database Syst Rev:Cd007630.

15. Smith TJ, Kahaly GJ, Ezra DG, Fleming JC, Dailey RA, Tang RA, Harris GJ, Antonelli A, Salvi M, Goldberg RA, Gigantelli JW, Couch SM, Shriver EM, Hayek BR, Hink EM, Woodward RM, Gabriel K, Magni G, Douglas RS 2017 Teprotumumab for Thyroid-Associated Ophthalmopathy. N Engl J Med 376:1748-1761.

16. Rajendram R, Taylor PN, Wilson VJ, Harris N, Morris OC, Tomlinson M, Yarrow S, Garrott H, Herbert HM, Dick AD, Cook A, Gattamaneni R, Jain R, Olver J, Hurel SJ, Bremner F, Drummond SR, Kemp E, Ritchie DM, Rumsey N, Morris D, Lane C, Palaniappan N, Li C, Pell J, Hills R, Ezra DG, Potts MJ, Jackson S, Rose GE, Plowman N, Bunce C, Uddin JM, Lee RWJ, Dayan CM 2018 Combined immunosuppression and radiotherapy in thyroid eye disease (CIRTED): a multicentre, $2 \times 2$ factorial, double-blind, randomised controlled trial. Lancet Diabetes Endocrinol 6:299-309. 
17. Draman MS, Ludgate M 2017 Thyroid eye disease- an update: Expert Review of Ophthalmology: Vol 11, No 4.

18. Hahn E, Laperriere N, Millar BA, Oestreicher J, McGowan H, Krema H, Gill H, DeAngelis D, Hurwitz J, Tucker N, Simpson R, Chung C 2014 Orbital radiation therapy for Graves' ophthalmopathy: measuring clinical efficacy and impact. Pract Radiat Oncol 4:233239.

19. Thapa S, Gupta AK, Gupta A, Gupta V, Dutta P, Virk RS 2015 Proptosis reduction by clinical vs radiological modalities and medial vs inferomedial approaches: comparison following endoscopic transnasal orbital decompression in patients with dysthyroid orbitopathy. JAMA Otolaryngol Head Neck Surg 141:329-334.

20. Draman MS, Grennan-Jones F, Zhang L, Taylor P, Kyaw Tun T, McDermott J, Moriarty P, Morris D, Lane C, Sreenan S, Dayan C, Ludgate M 2013 Prostaglandin F2alpha (PGF2alpha) Effects on Adipocyte Biology Relevant to Graves' Orbitopathy. Thyroid.

21. Choi HG, Park YM, Lu Y, Chang HW, Na M, Lee SH 2013 Inhibition of prostaglandin $D(2)$ production by trihydroxy fatty acids isolated from Ulmus davidiana var. japonica. Phytother Res 27:1376-1380.

22. Draman MS, Ludgate M 2011 Pathogenesis of Graves Orbitopathy. Immunology, Endocrine $\{\backslash \&\}$ Metabolic Agents in Medicinal Chemistry 11:72--82.

23. Potgieser PW, Wiersinga WM, Regensburg NI, Mourits MP 2015 Some studies on the natural history of Graves' orbitopathy: increase in orbital fat is a rather late phenomenon. Eur J Endocrinol 173:149-153.

24. Kim HW, Choi YJ, Lee KW, Lee MJ 2017 Periorbital changes associated with prostaglandin analogs in Korean patients BMC Ophthalmol. Vol 17.

25. Regensburg NI, Wiersinga WM, Berendschot TT, Potgieser P, Mourits MP 2011 Do subtypes of graves' orbitopathy exist? Ophthalmology 118:191-196. 


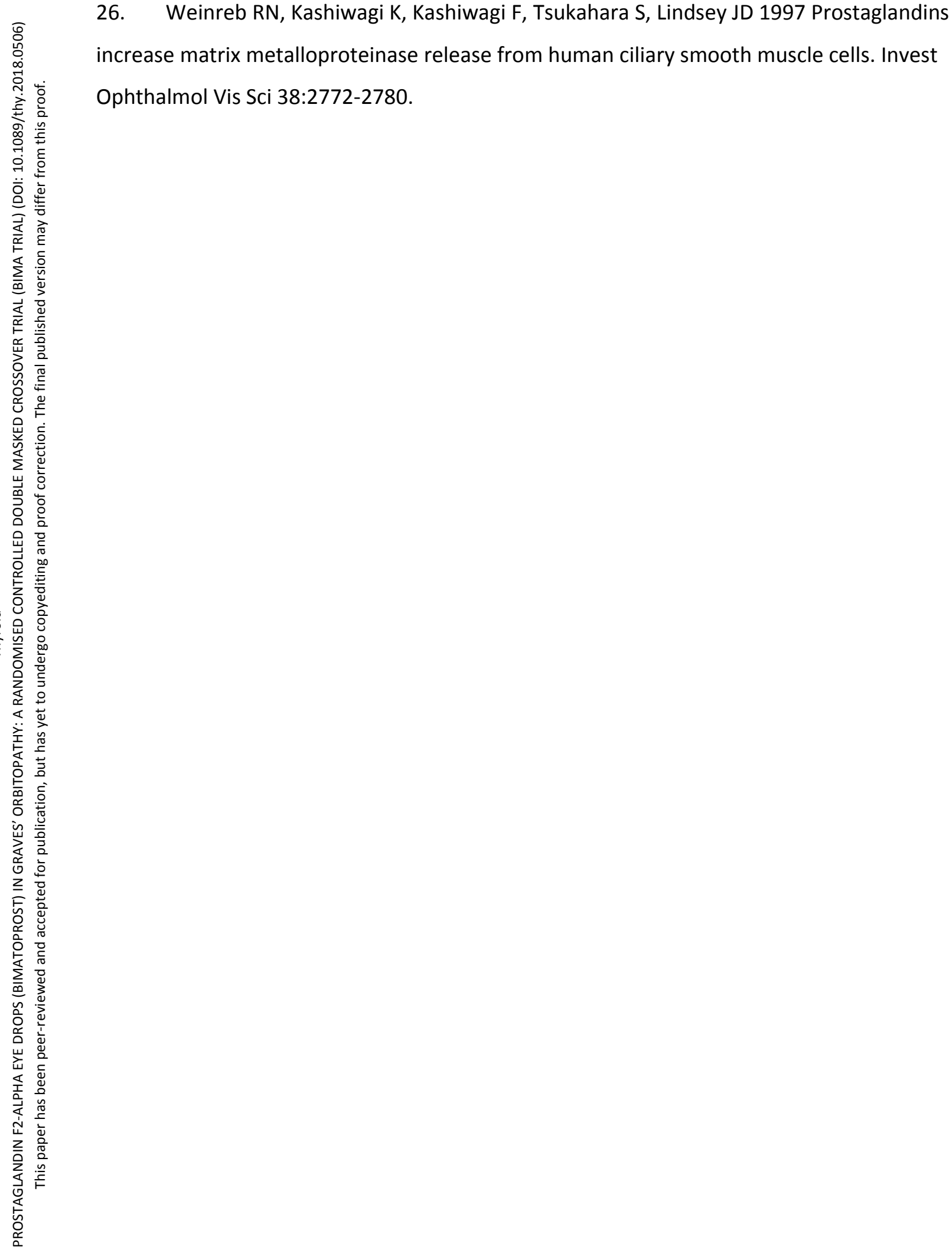


Table 1: Baseline demographics of the study population. Data presented as means (standard deviation or range) unless stated otherwise or \% (patient number/total).

\begin{tabular}{|c|c|c|c|}
\hline Treatment allocations & All patients & $\begin{array}{l}\text { Bimatoprost first } \\
n=16\end{array}$ & $\begin{array}{l}\text { Placebo first } \\
n=15\end{array}$ \\
\hline Female (\%) & $83.9(26 / 31)$ & $87.5(14 / 16)$ & $80.0(12 / 15)$ \\
\hline Caucasian (\%) & $93.5(29 / 31)$ & $87.5(14 / 16)$ & $100(15 / 15)$ \\
\hline Age (years), mean (range) & $55.2(28-74)$ & $55.2(31-70)$ & $55.2(28-74)$ \\
\hline $\mathrm{BMI}(\mathrm{kg} / \mathrm{m} 2)$ & $29.0(6.5)$ & $28.8(6.3)$ & $29.2(7.0)$ \\
\hline $\begin{array}{l}\text { Symptom duration before } \\
\text { diagnosis (months), median } \\
\text { (IQR) }\end{array}$ & $4.0(1-6)$ & $3.5(2-6.5)$ & $4.0(1-6)$ \\
\hline $\begin{array}{l}\text { GO Duration (years), median } \\
\text { (IQR) }\end{array}$ & $7.6(3.6-12.3)$ & $8.8(3.5-14.4)$ & $7.1(4.3-12.3)$ \\
\hline Smokers at diagnosis (\%) & $74.2(23 / 31)$ & $81.2(13 / 16)$ & $66.7(10 / 15)$ \\
\hline Current smoking (\%) & $38.7(12 / 31)$ & $37.5(6 / 16)$ & $40.0(6 / 15)$ \\
\hline $\begin{array}{l}\text { No. cigarettes/week, median } \\
\text { (IQR) }\end{array}$ & $70(10-105)$ & $70(2-70)$ & $70(14-140)$ \\
\hline FT4 (pmol/L), median (IQR) & $15.9(13.5-17.4)$ & $16.7(15.9-18.4)$ & $13.9(12.5-15.2)$ \\
\hline $\mathrm{TSH}(\mathrm{mU} / \mathrm{L})$, median (IQR) & $0.87(0.12-2.6)$ & $0.76(0.15-1.22)$ & $1.45(0.12-5.33)$ \\
\hline Total Diplopia (\%) & $61.3(19 / 31)$ & $62.5(10 / 16)$ & $60.0(9 / 15)$ \\
\hline Intermittent & $25.8(8 / 31)$ & $18.8(3 / 16)$ & $33.3(5 / 15)$ \\
\hline Inconstant (gaze-evoked) & $16.1(5 / 31)$ & $12.5(2 / 16)$ & $20.0(3 / 15)$ \\
\hline
\end{tabular}




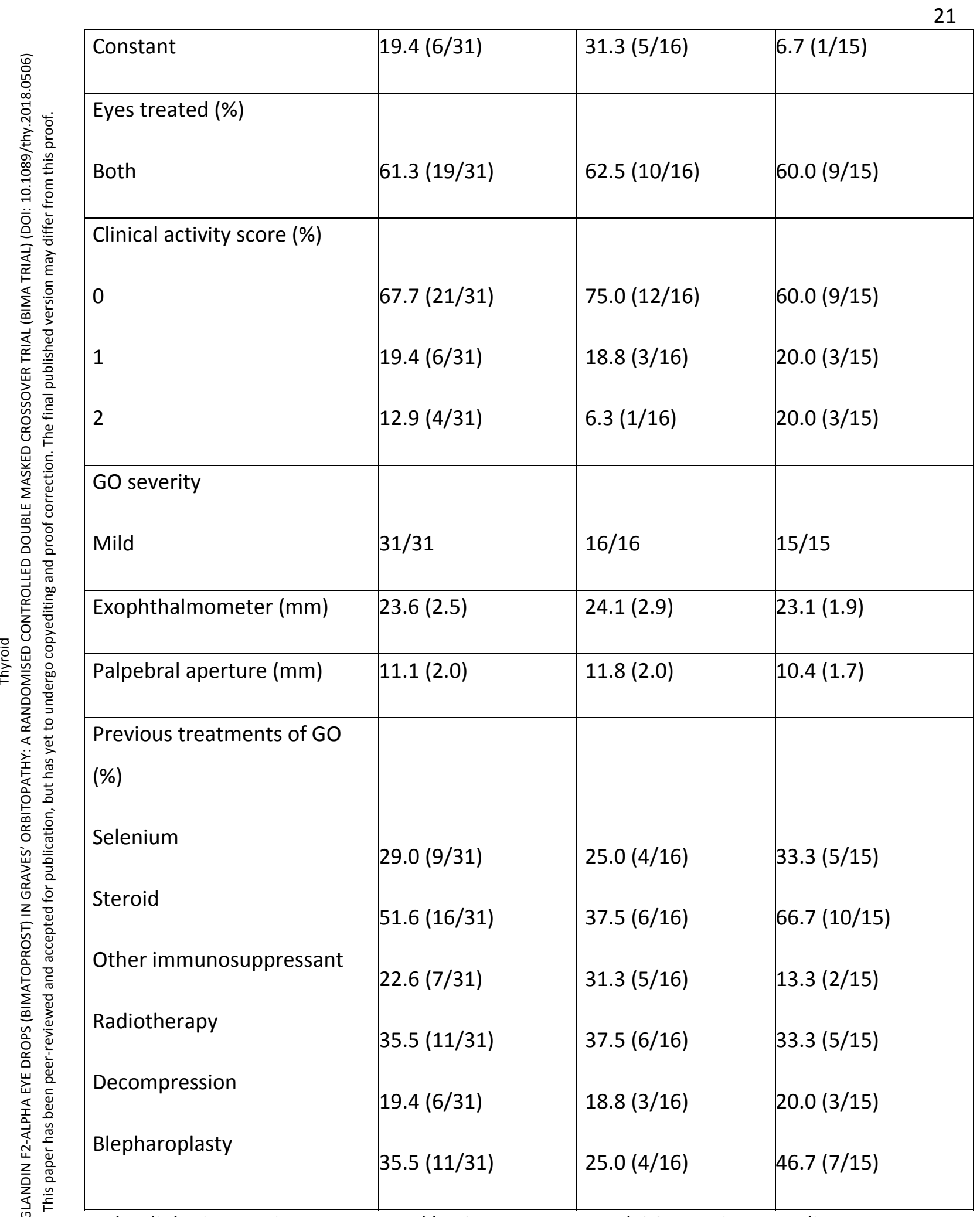

The diplopia severity was assessed by Gorman score and GO severity according to EUGOGO criteria. BMI, body mass index; IQR, interquartile range; FT4 (9.0-19.1 pmol/I); TSH (0.30-4.4 mU/l). 
Table 2: Beta coefficient of Bimatoprost effect on exophthalmometer readings using multilevel modeling with each treated patient's eye within the patient. Minus protocol deviation indicated 3 patients removed from the analysis due to the stated reason. Minus IOP non-responder indicated removal of eyes from analysis with at least a $10 \%$ reduction in intraocular pressure (surrogate marker to compliance).
Model
$\mathrm{N}$
Eye
Outcome
$95 \% \mathrm{Cl}$
$p$ value
(numbers) data points coefficient

\section{All patients}

Model 1

31

50

96

$-0.22$

$-0.75,0.32 \quad 0.424$

Model $2 \quad 31$

50

96

$-0.17$

$-0.67,0.32 \quad 0.490$

Model $3 \quad 31$

50

96

$-0.16$

$-0.64,0.33 \quad 0.531$

Minus protocol deviation

Model $1 \quad 28$

46

88

$-0.06$

$-0.60,0.47 \quad 0.814$

Model 28

46

88

$-0.06$

$-0.56,0.45 \quad 0.827$

Model $3 \quad 28$

46

88

$-0.04$

$-0.55,0.46 \quad 0.861$

Minus IOP non-responder (10\% IOP drop)

Model $1 \quad 27$

46

88

$-0.37$

$-0.94,0.19 \quad 0.192$

Model $2 \quad 27$

46

88

$-0.29$

$-0.81,0.24$

0.283

Model 3

27

46

88

$-0.27$

$-0.78,0.25 \quad 0.313$

Model 1 Adjusted for baseline

Model 2 Adjusted for baseline, phase and carryover.

Model 3 Adjusted for baseline phase, carryover and assessors.

$\mathrm{N}=$ Number of patients in the model. 
Table 3: Patient-reported ocular side effects.

\begin{tabular}{|c|c|c|c|}
\hline \multicolumn{4}{|l|}{ Ocular side effects } \\
\hline & $\begin{array}{l}\text { Bimatoprost } \\
\text { n (\%) }\end{array}$ & $\begin{array}{l}\text { Placebo } \\
\text { n (\%) }\end{array}$ & $\begin{array}{l}\text { Fisher exact } \\
\text { P value }\end{array}$ \\
\hline $\begin{array}{l}\text { Conjunctival } \\
\text { hyperemia }\end{array}$ & $10(32.3)$ & $3(9.7)$ & 0.029 \\
\hline Eye pruritus & 4 (12.9) & $1(3.2)$ & 0.177 \\
\hline Eyelid swelling & $3(9.7)$ & $2(6.5)$ & 0.500 \\
\hline Visual disturbance & $2(6.5)$ & 0 & 0.245 \\
\hline Meibomian cyst & $2(6.5)$ & $2(6.5)$ & 0.694 \\
\hline Burning sensation & $1(3.2)$ & $1(3.2)$ & 0.754 \\
\hline Eye dryness & $1(3.2)$ & $1(3.2)$ & 0.500 \\
\hline Eyelid pigmentation & $1(3.2)$ & 0 & 0.500 \\
\hline Conjunctivitis & $1(3.2)$ & 0 & 0.500 \\
\hline $\begin{array}{l}\text { Foreign body } \\
\text { sensation }\end{array}$ & 0 & $1(3.2)$ & 0.500 \\
\hline Eye pain & 0 & $1(3.2)$ & 0.500 \\
\hline Ptosis & 0 & $1(3.2)$ & 0.500 \\
\hline $\begin{array}{l}\text { Difficulty eye } \\
\text { opening }\end{array}$ & 0 & $1(3.2)$ & 0.500 \\
\hline
\end{tabular}

The percentage was calculated from the total number of patients in the trial $(\mathrm{N}=31)$. 


\section{Figure legends}
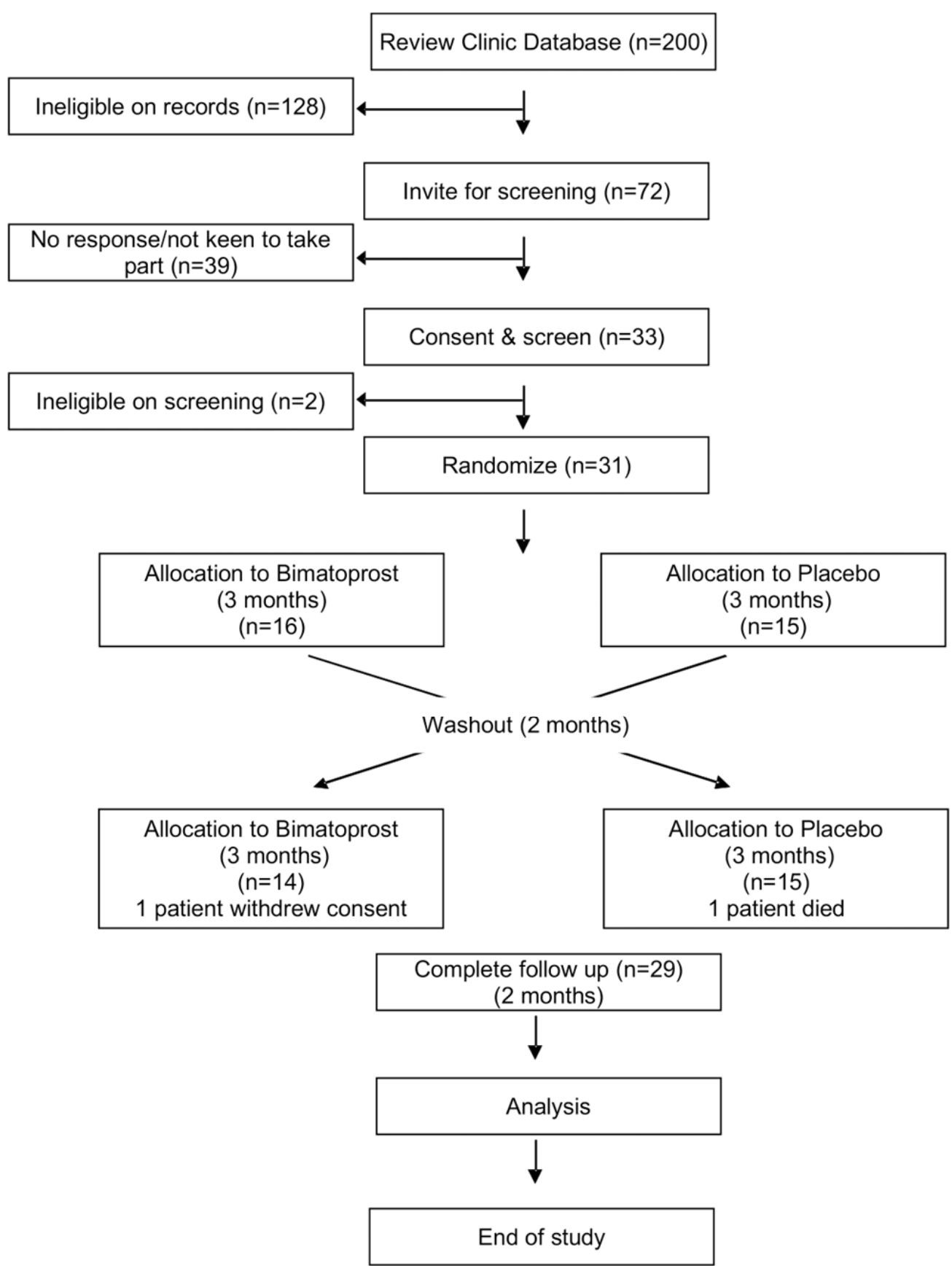

Trial participants were randomised to receive Bimatoprost or placebo ( $n=$ number of participants at each stage). One patient from Bimatoprost starting group died during washout period from pulmonary embolism and one patient from placebo starting group did not complete final 2 trial visits.

Figure 1: Study consort diagram. 


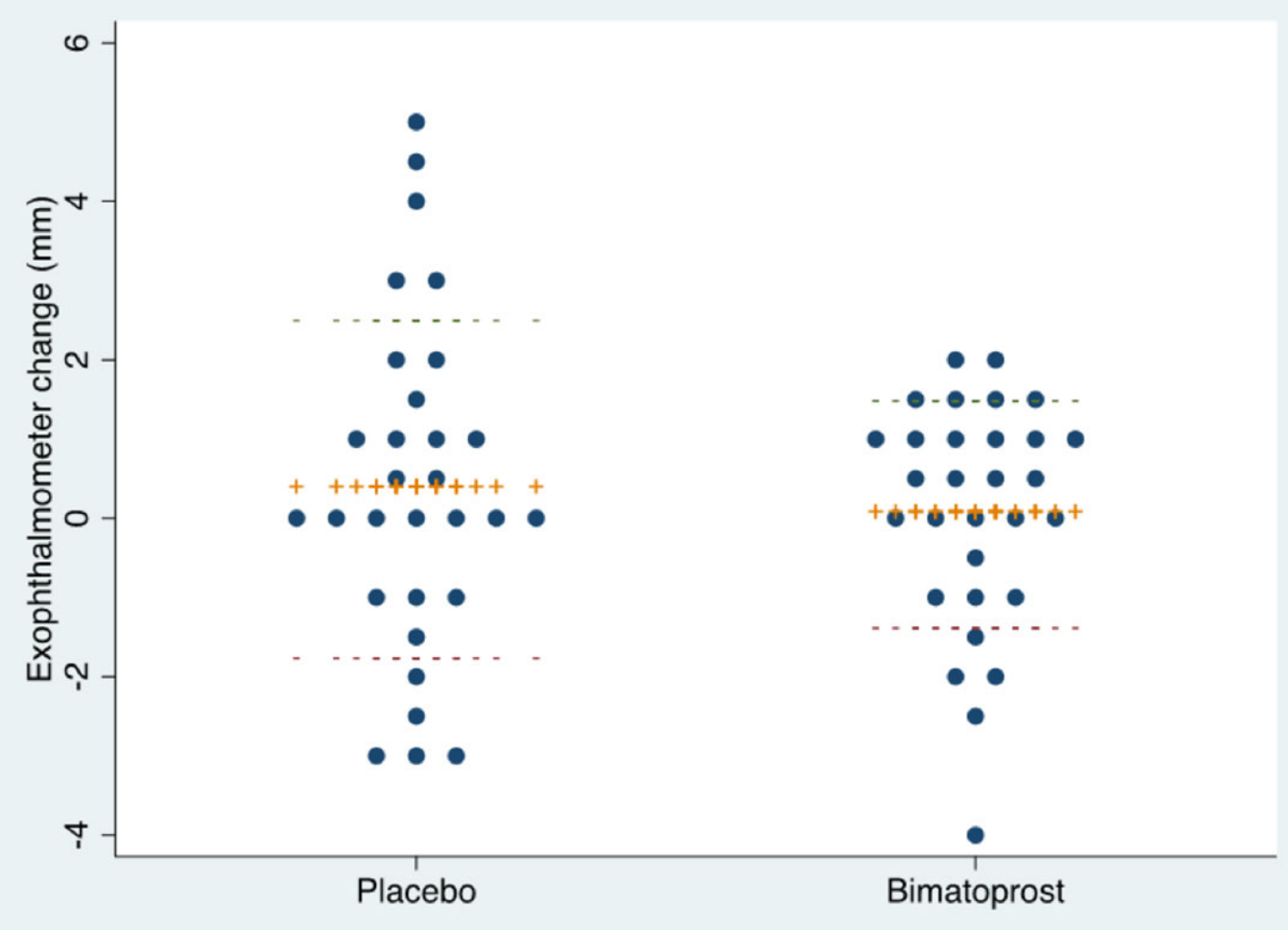

Figure 2: Dot plot of the mean change in proptosis measurement in the placebo phase and Bimatoprost phase expressed in millimeters. The mean change in measurement was calculated by subtracting the baseline measurement from that following treatment. Therefore, negative value Table 1: Baseline demographics of the study population. Data presented as means (standard deviation or range) unless stated otherwise or \% (patient number/total) indicates an improvement in the treatment. The ++ represents mean and the - represents standard deviation. Paired t-test $p$ value $=0.8455$. 


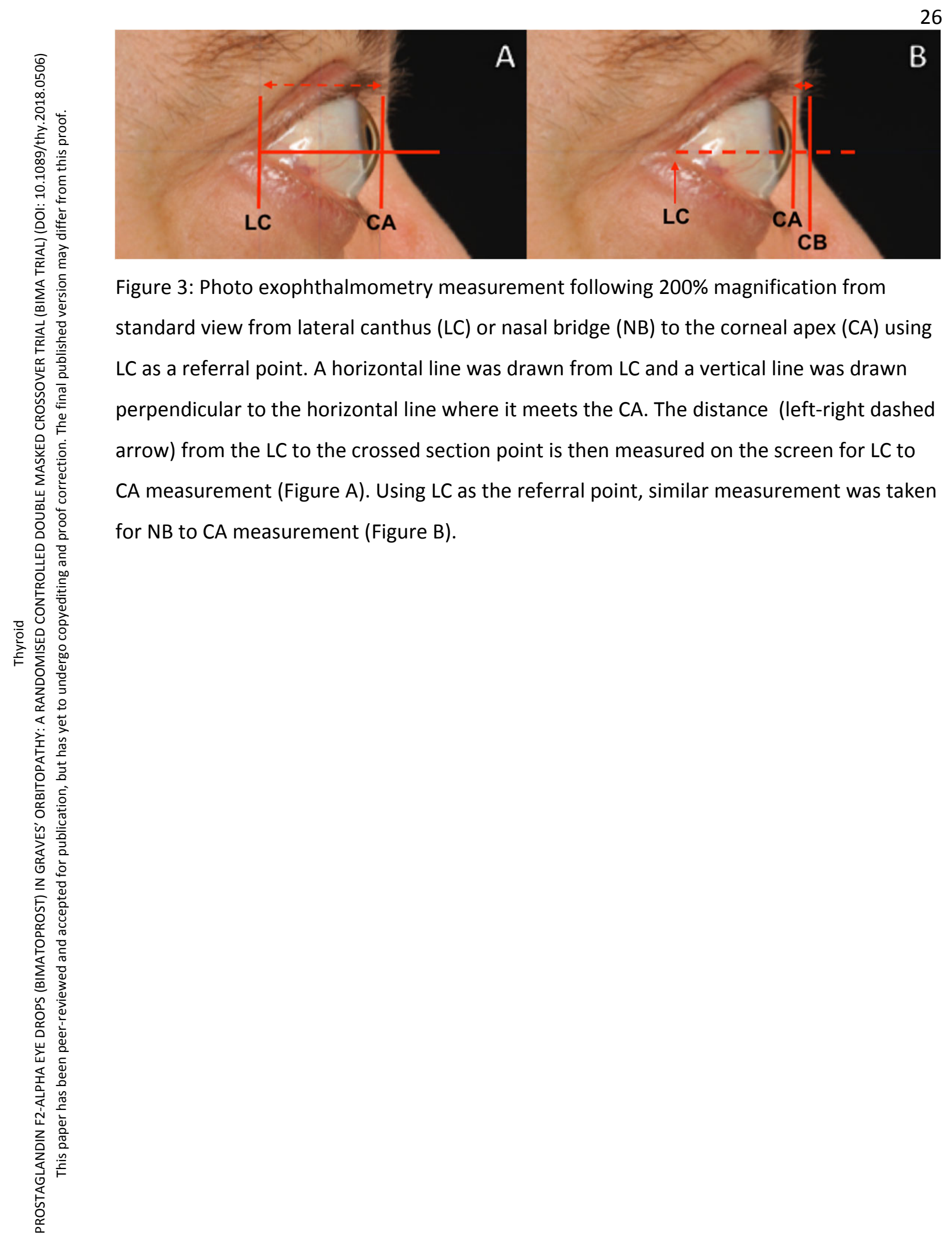



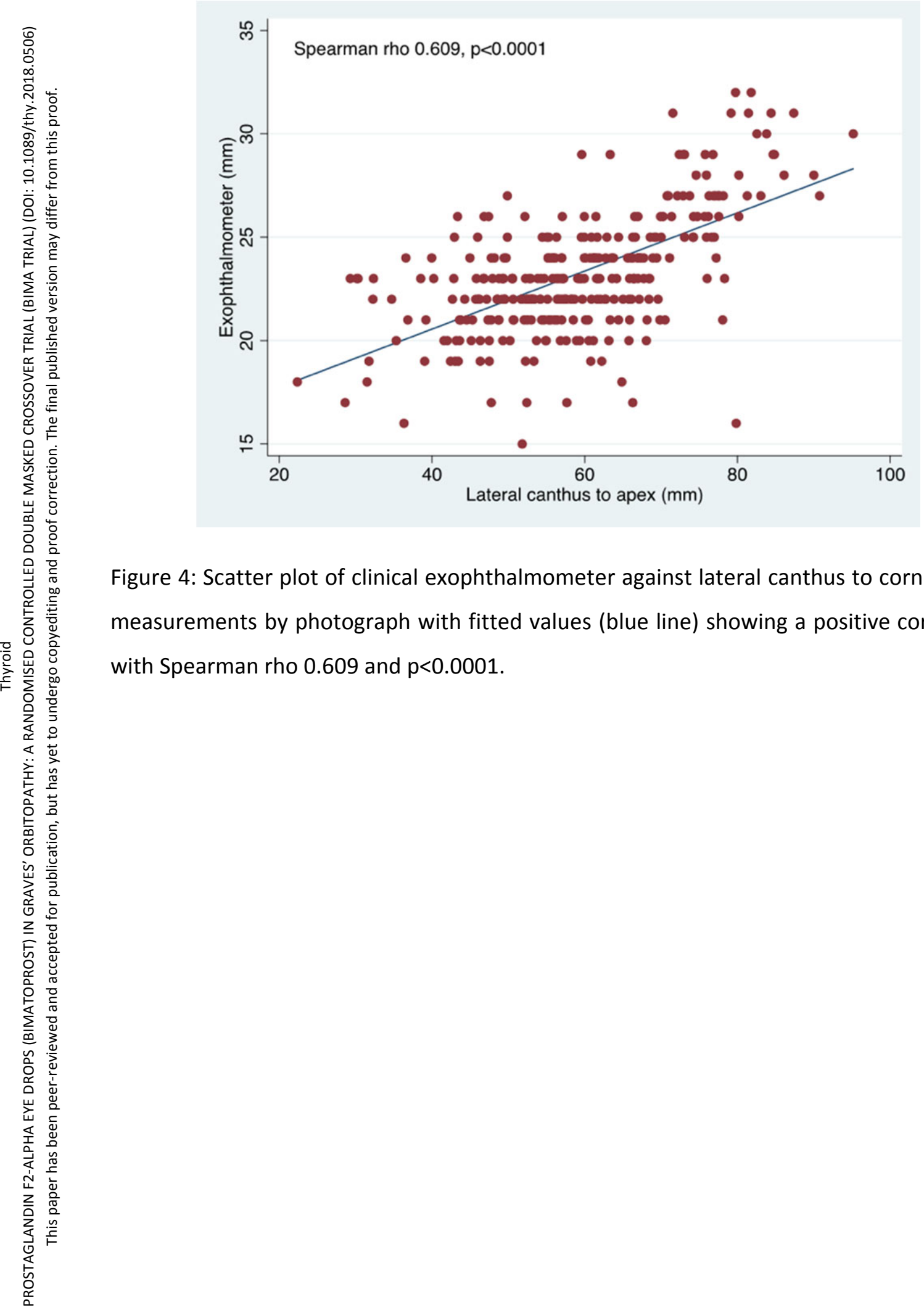

Figure 4: Scatter plot of clinical exophthalmometer against lateral canthus to corneal apex measurements by photograph with fitted values (blue line) showing a positive correlation with Spearman rho 0.609 and $p<0.0001$. 


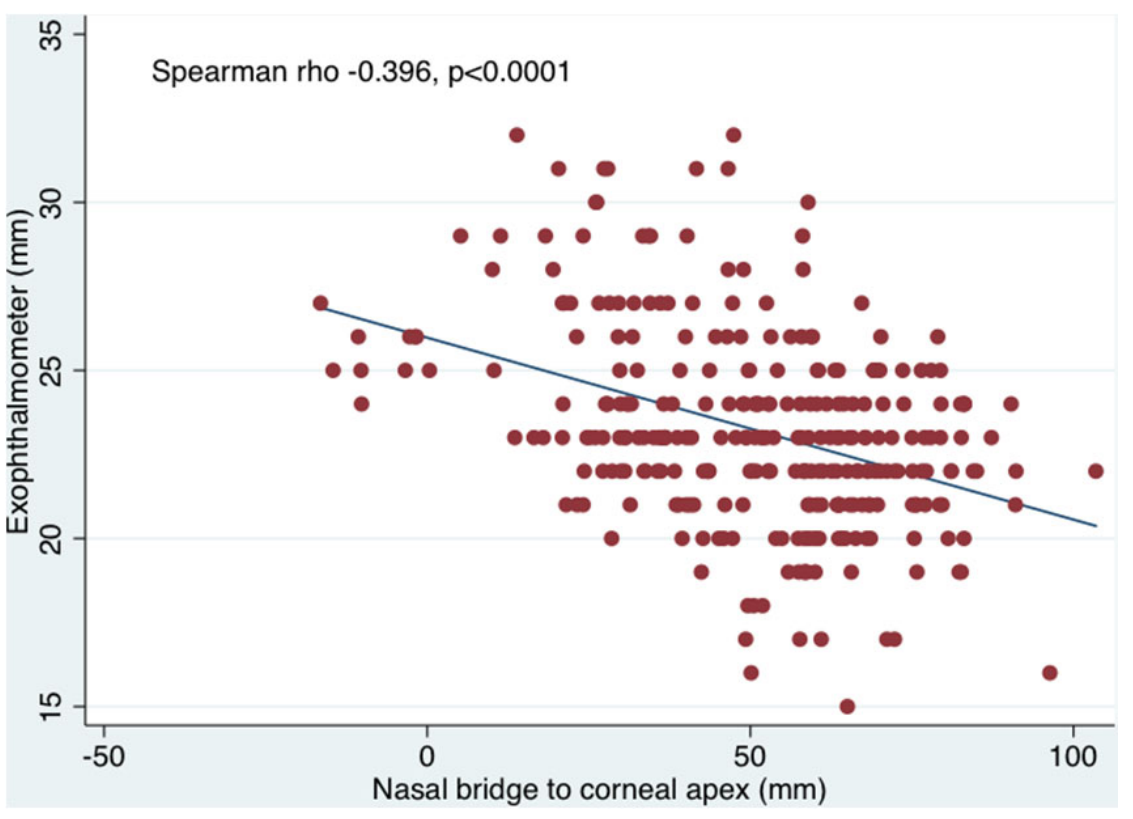

Figure 5: Scatter plot of clinical exophthalmometer against the nasal bridge to corneal apex measurements by photograph with fitted values (blue line) showing a negative correlation with Spearman rho -0.396 and $p<0.0001$. 

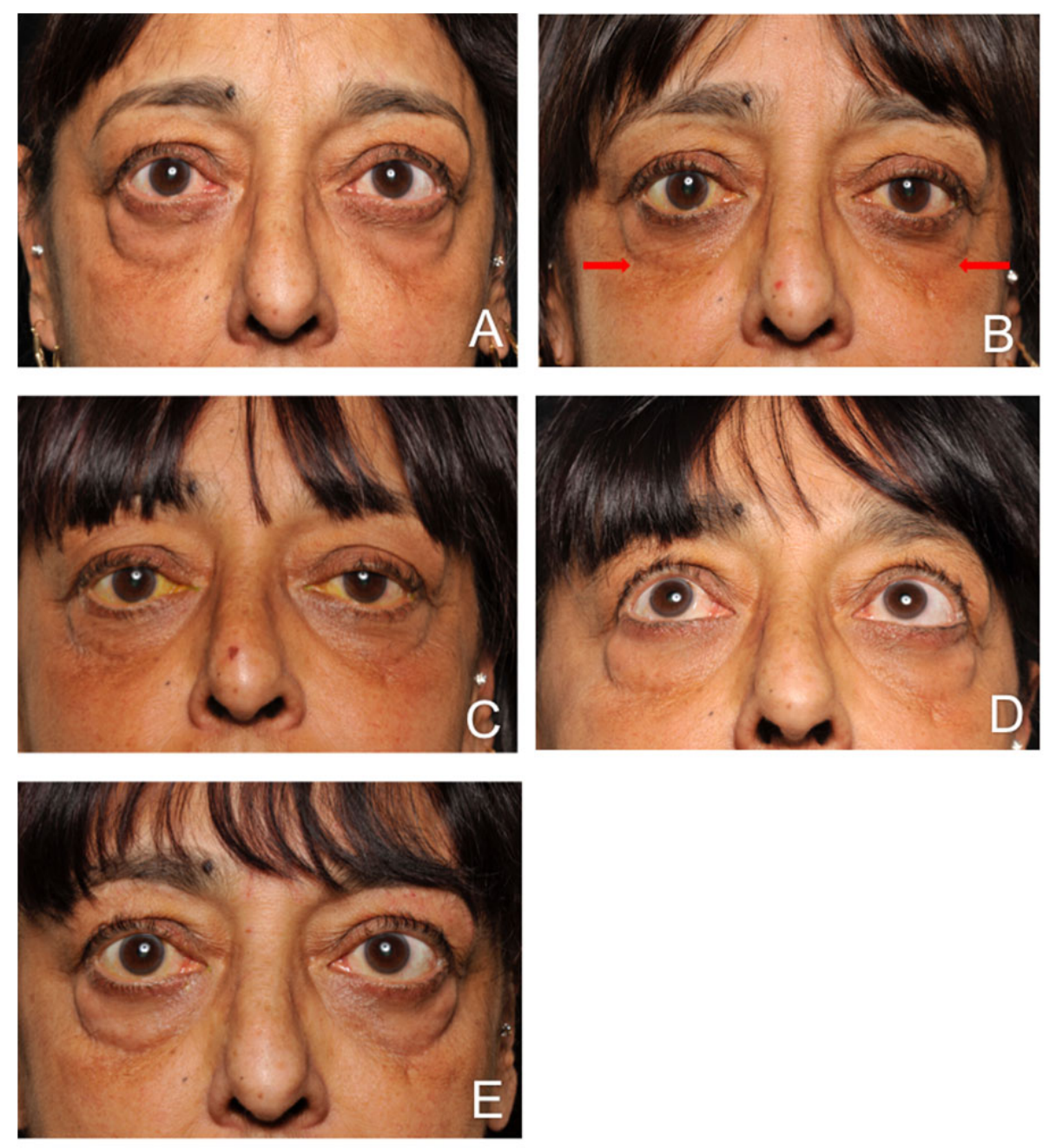

Figure 6: Photo of 1 patient with lower lid periorbital fat atrophy. Following 3 months on Bimatoprost, there was a reduction of $3 \mathrm{mmHg}$ in IOP in both eyes with $2 \mathrm{~mm}$ exophthalmometer reduction of the right eye and $1 \mathrm{~mm}$ of the left eye. These then returned to baseline following 2 months' washout period. A: Baseline. B: Bilateral lower lid fat atrophy (red arrow) following 3 months' course of Bimatoprost. C: 2 months following the washout period, D: 3 months on placebo. E, end of the trial visit. 
STANDARD OPERATING PROCEDURE: CLINICAL IMAGES FOR BIMA STUDY

This Standard Operating Procedure (SOP) provides guidelines to ensure repeatability and validity of images used in Bima Study at University Hospital of Wales. Use of guidelines will also allow different photographers to achieve consistent results.

- Photos will be taken at visit 1, 2, 3, 4 and 5 of study visits. This will normally be on Thursday afternoon clinic.

- Trial manager will inform Media Resources of patient visit and approximate time of patient arrival at least 1 week prior to ensure that a slot is available for the patient.

- Media Resources Centre will close between 1-1:30pm daily and the latest study patient referral is at 4:30pm.

- A GREEN request form for clinical photography must be filled either by clinical research fellow or trial manager. The followings should be noted (See sample below).

- Use patient addressograph

○ Consultant: Mrs. Lane

- Phone: (Phone number of the clinic room or office number)

○ Diagnosis: BIMA Study (DO NOT put thyroid eye disease as patient will be treated as non-trial patient)

○ Patient Study ID No: (e.g. 1001)

○ Visit number: (e.g. visit 1)

- Patient to sign consent form

- Requester information (Name, position, signature and date)

- All serial photographs will be recorded using standard Cardiff and Vale UHB Media Resources Center imaging system in the studio (Located on upper ground floor between A \& B block):

Nikon D700 with 105 mm NIKON lens

Studio lighting 
Ensuring Repeatability:

- All digital images for the medical record will be saved as JPEG. Changes in pixel resolution will not be made.

- Each view to be imaged will be identified with the following terminology:

- Primary position (PP)

- Eye closed (EC)

○ Look up (LU)

○ Look down (LD)

○ Lateral left (LL)

$\circ \quad$ Lateral right (LR)

- Each view will be photographed at 1:4 scale.

- Image will be saved to BIMA study folder on UHB secure server in line with Cardiff and Vale UHB IT security policy. Each patient will have their own folder. File name will conform to the following naming convention (STUDY ID_VISIT NUMBER_VIEW) e.g. for patient ID 1001, visit 3 and with primary position (PP) view: File should be named as 1001_3_PP.

- A record that photographs have been taken will be made in clinical record form (CRF) by the clinical research fellow or trial manager at each appropriate visit. 


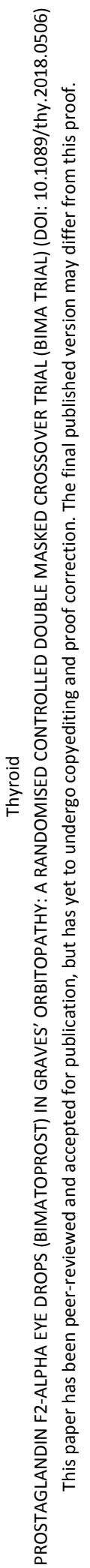

Sample photos
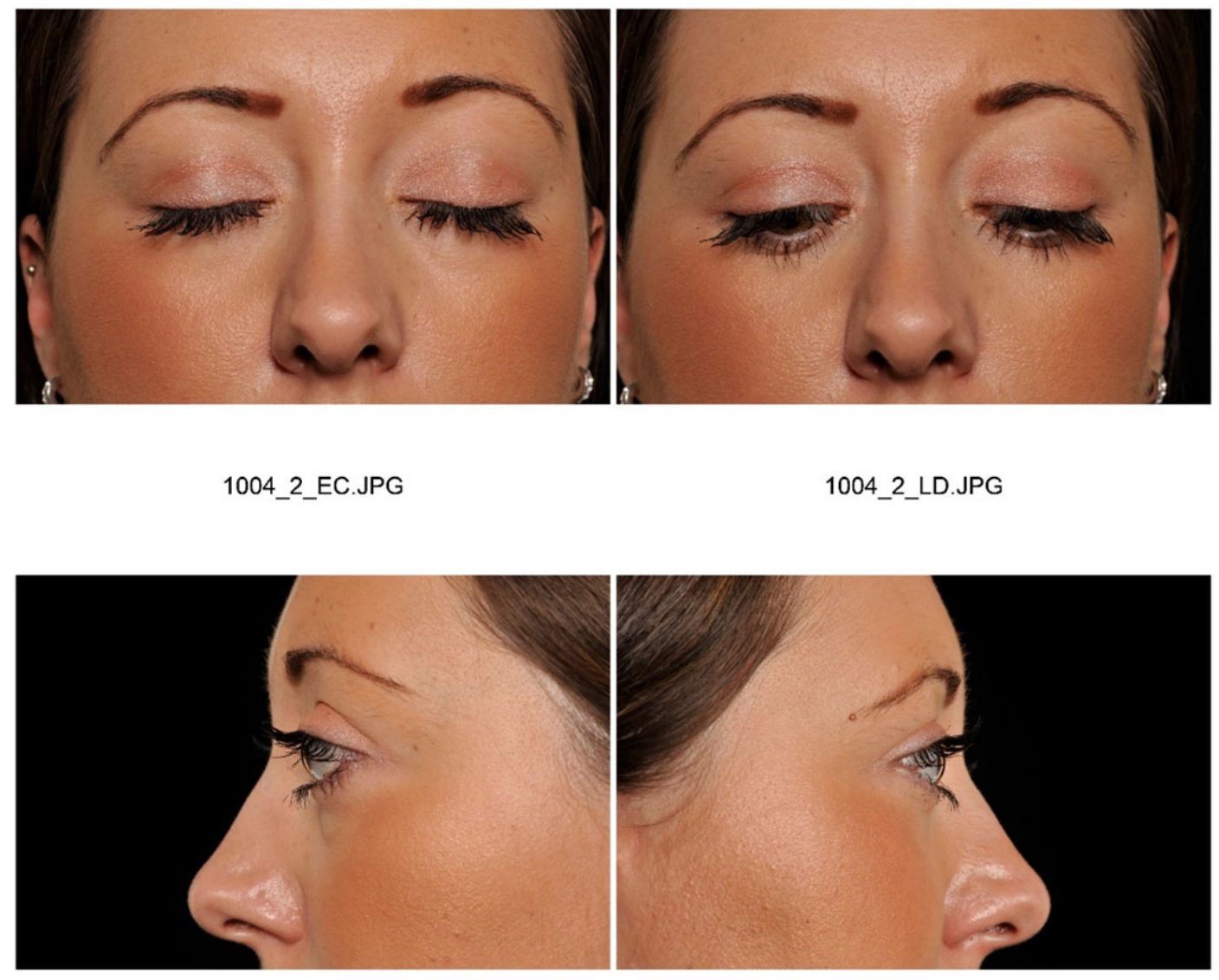

1004_2_LL.JPG

1004_2_LR.JPG
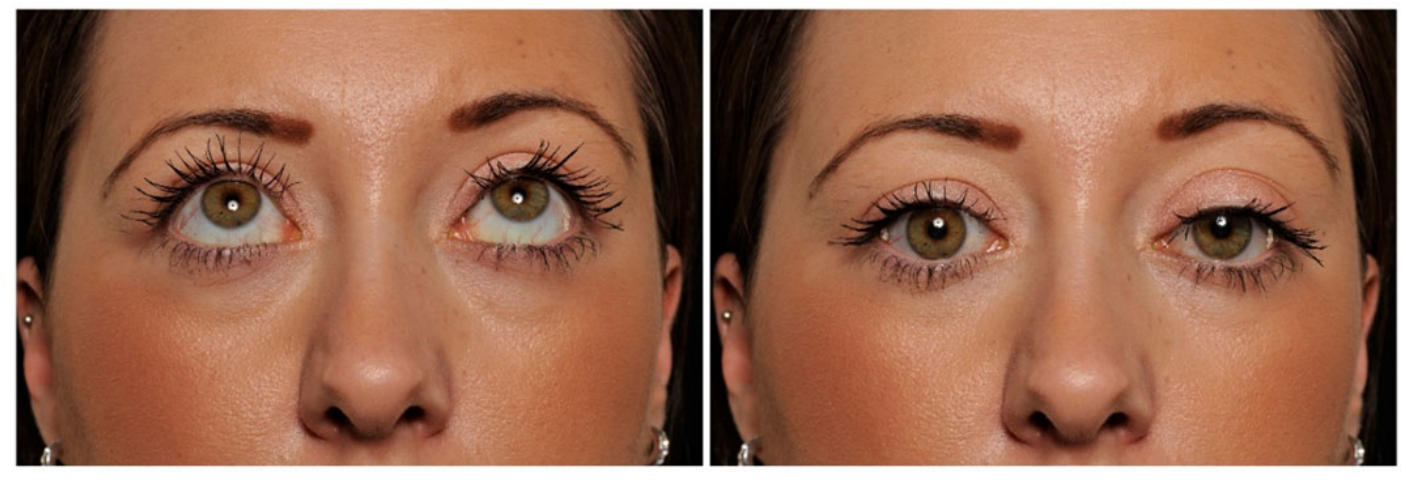

1004_2_LU.JPG

1004_2_PP.JPG 
Supplementary tables and figures

\begin{tabular}{|c|c|c|c|c|c|}
\hline \multicolumn{6}{|c|}{$\begin{array}{l}\text { Supplementary table 1: The mean exophthalmometer readings of the treated eye } \\
\text { throughout trial visits. "Obs" indicates number of observations. }\end{array}$} \\
\hline Visit & Obs & Mean $(\mathrm{mm})$ & Std. Dev. & Min & Max \\
\hline 1 & 31 & 23.6 & 2.5 & 20 & 30.5 \\
\hline 2 & 31 & 23.4 & 2.7 & 18 & 30 \\
\hline 3 & 30 & 23.1 & 2.7 & 19 & 29 \\
\hline 4 & 29 & 23.7 & 2.9 & 19 & 31 \\
\hline 5 & 29 & 23.9 & 2.6 & 20 & 31.5 \\
\hline
\end{tabular}


Supplementary table 2: Patient reported non-ocular side effects.

\begin{tabular}{|c|c|c|c|}
\hline \multicolumn{4}{|c|}{ Non-ocular side effects } \\
\hline & $\begin{array}{c}\text { Bimatoprost } \\
\text { n (\%) }\end{array}$ & $\begin{array}{l}\text { Placebo } \\
\text { n (\%) }\end{array}$ & $\begin{array}{c}\text { Fisher exact } \\
\text { P value }\end{array}$ \\
\hline Pain (total) & $16(51.6)$ & $2(6.5)$ & $<0.001$ \\
\hline Pain headache & $9(29.0)$ & $2(6.5)$ & 0.021 \\
\hline Infection & $3(9.7)$ & $1(3.2)$ & 0.306 \\
\hline Sinus & $3(9.7)$ & 4 (12.9) & 0.500 \\
\hline Flu-like syndrome & $1(3.2)$ & $1(3.2)$ & 0.754 \\
\hline Urticarial & $1(3.2)$ & $1(3.2)$ & 0.754 \\
\hline Bronchospasm & $1(3.2)$ & 0 & 0.500 \\
\hline Osteoarthritis & $1(3.2)$ & 0 & 0.500 \\
\hline Dizziness & 0 & $1(3.2)$ & 0.500 \\
\hline Heartburn & $2(6.5)$ & 0 & 0.246 \\
\hline Musculoskeletal & $1(3.2)$ & 0 & 0.500 \\
\hline Polydipsia & 0 & $1(3.2)$ & 0.500 \\
\hline Tooth ache & $1(3.2)$ & 0 & 0.500 \\
\hline Urine colour change & 0 & $1(3.2)$ & 0.500 \\
\hline Diarrhoea/vomiting & $1(3.2)$ & 0 & 0.500 \\
\hline Joint pain & 0 & $2(6.5)$ & 0.246 \\
\hline
\end{tabular}

Percentage was calculated from total number of patients in the trial $(\mathrm{N}=31)$. 
Supplementary table 3: Frequency of detectable side effects (percentage) recorded by masked assessor on photographic assessment.

\begin{tabular}{|c|c|c|c|c|}
\hline \multirow{2}{*}{\multicolumn{2}{|c|}{ Side effects }} & \multicolumn{2}{|c|}{ Treatment } & \multirow{2}{*}{$p$ value } \\
\hline & & Placebo & Bimatoprost & \\
\hline \multicolumn{2}{|c|}{ Iris colour changes } & $0(0)$ & $1(3.2)$ & 0.3134 \\
\hline \multicolumn{2}{|c|}{ Skin colour changes } & $1(3.2)$ & $10(32.3)$ & 0.0028 \\
\hline \multicolumn{2}{|c|}{ Eye lashes elongation } & $2(6.5)$ & $18(58.1)$ & 0.0001 \\
\hline \multirow[t]{3}{*}{ Redness } & Conjunctival & $3(9.7)$ & $8(25.8)$ & 0.0965 \\
\hline & Upper lid & $3(9.7)$ & $10(32.3)$ & 0.0290 \\
\hline & Lower lid & $1(3.2)$ & $7(22.6)$ & 0.0230 \\
\hline \multirow{2}{*}{$\begin{array}{l}\text { Fat } \\
\text { atrophy }\end{array}$} & Upper lid & $0(0)$ & $1(3.2)$ & 0.3134 \\
\hline & Lower lid & $0(0)$ & $1(3.2)$ & 0.3134 \\
\hline
\end{tabular}


Supplementary table 4: Health economics consumption comparison

\begin{tabular}{|c|c|c|c|c|c|c|}
\hline \multirow[b]{2}{*}{ Post } & \multicolumn{2}{|c|}{2 months period } & \multicolumn{2}{|c|}{2 months period } & \multicolumn{2}{|c|}{ All (4 months period) } \\
\hline & $\begin{array}{l}\text { Bimatopr } \\
\text { ost }\end{array}$ & Placebo & $\begin{array}{l}\text { Bimatopr } \\
\text { ost } \\
\text { washout }\end{array}$ & $\begin{array}{l}\text { Placebo } \\
\text { washout }\end{array}$ & $\begin{array}{l}\text { Bimatopros } \\
\mathrm{t}\end{array}$ & Placebo \\
\hline $\begin{array}{l}\text { Total drug } \\
\text { cost } \\
\text { Median/m } \\
\text { ean } \\
\text { (range) }\end{array}$ & $\begin{array}{l}£ 6.14 / f 9 . \\
71 \\
(0.00- \\
70.12)\end{array}$ & $\begin{array}{l}£ 5.68 / £ 11 \\
.81 \\
(0.00- \\
65.92)\end{array}$ & $\begin{array}{l}£ 6.14 / £ 1 \\
2.93 \\
(0.00- \\
65.92)\end{array}$ & $\begin{array}{l}f 6.02 / f 9 . \\
42 \\
(0.00- \\
65.92)\end{array}$ & $\begin{array}{l}f 12.36 / f 22 \\
.41 \\
(0.00- \\
136.04)\end{array}$ & $\begin{array}{l}£ 10.85 / £ 21 \\
.24 \\
(0.00- \\
131.84)\end{array}$ \\
\hline $\begin{array}{l}\text { Total NHS } \\
\text { encounter } \\
\text { cost } \\
\text { Median/m } \\
\text { ean } \\
\text { (range) }\end{array}$ & $\begin{array}{l}£ 0.00 / £ 5 \\
7.49 \\
(0.00- \\
253.20)\end{array}$ & $\begin{array}{l}£ 7.80 / £ 79 \\
.12 \\
(0.00- \\
567.00)\end{array}$ & $\begin{array}{l}£ 7.80 / £ 6 \\
6.93 \\
(0.00- \\
275.60)\end{array}$ & $\begin{array}{l}f 4.30 / £ 75 \\
.09 \\
(0.00- \\
428.40)\end{array}$ & $\begin{array}{l}£ 86.60 / £ 12 \\
4.59 \\
(0.00- \\
528.80)\end{array}$ & $\begin{array}{l}£ 67.80 / £ 15 \\
4.21 \\
(0.00- \\
995.40)\end{array}$ \\
\hline
\end{tabular}




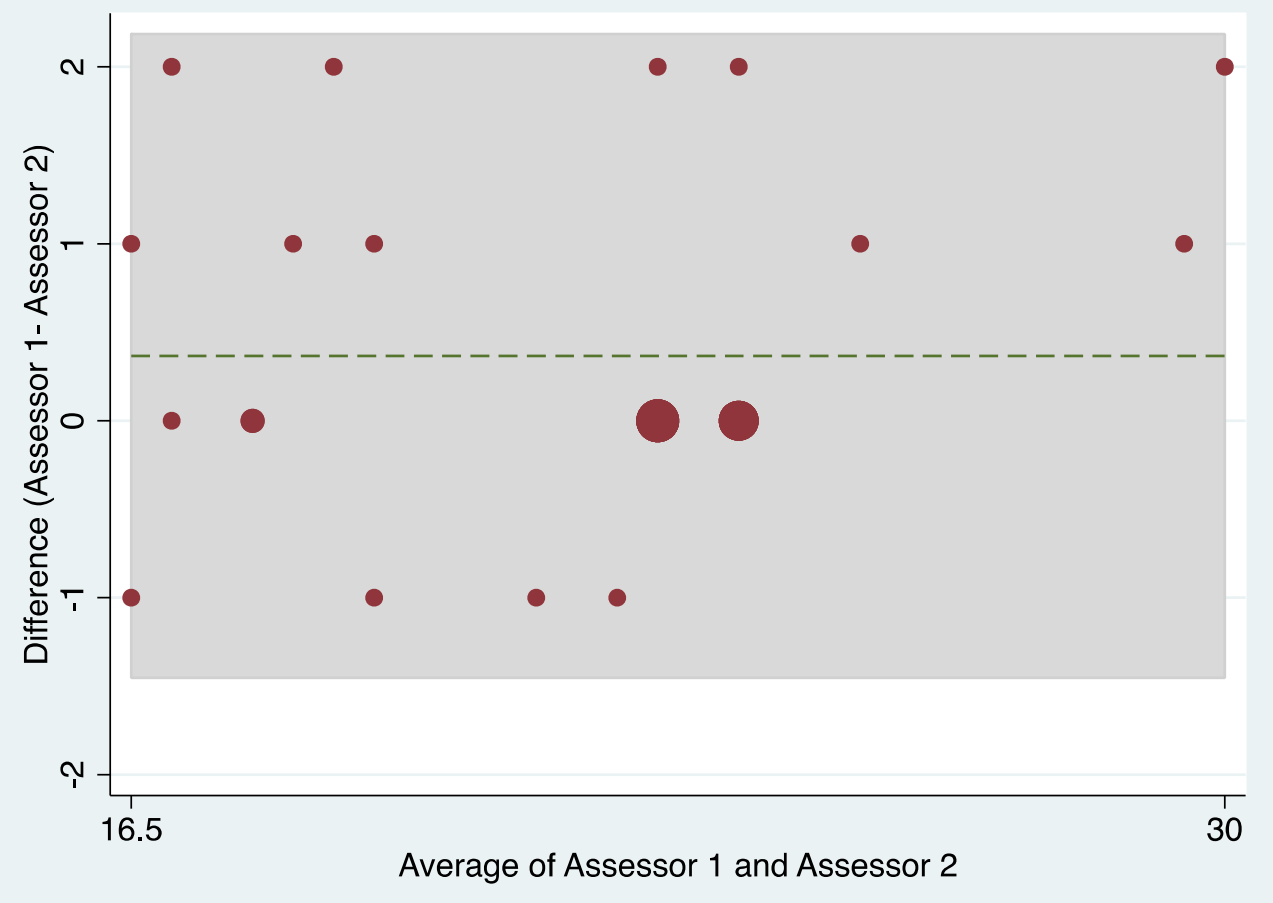

Supplementary figure 1: Bland Altman plot of differences between assessor 1 and assessor 2 versus the mean of the 2 assessors. 
Page 38 of 38
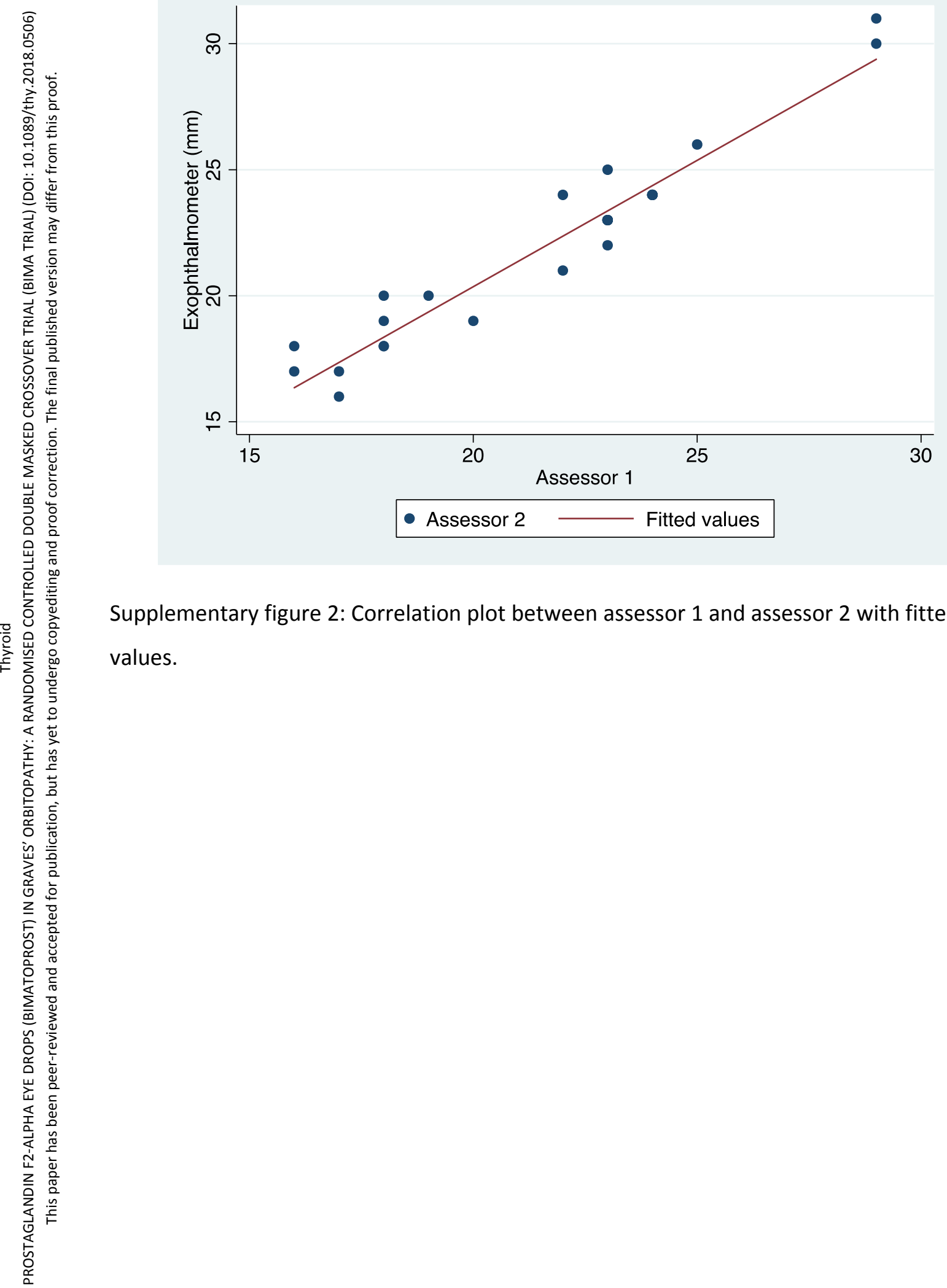

Supplementary figure 2: Correlation plot between assessor 1 and assessor 2 with fitted values. 